\title{
Aplication of Multi-Criteriaanalysis for Circuit Breaker Selection on Nigerian National Grid
}

\author{
Muhammed A. Tijani ${ }^{1}$, Gafari A. Adepoju ${ }^{2}$, Kazeem A. Hamzat ${ }^{3}$, Kayode O. \\ Olawale. \\ ${ }^{I}$ (Electrical/Electronic Engineering Department, Federal Polytechnic, Ede, Nigeria.) \\ ${ }^{2}$ (Department of Electronic \& Electrical Engineering, Ladoke Akintola University of Technology, Ogbomoso, \\ Nigeria.) \\ ${ }^{3}$ (Electrical/Electronic Engineering Department, Osun State College of Technology, Esa-Oke, Nigeria.) \\ ${ }^{4}$ (Science Laboratory Technology Department, Federal Polytechnic, Ede, Nigeria.)
}

\begin{abstract}
Power System Fault Analysis of The Nigerian 330kV Transmission Grid is a study of the determination of the appropriate circuit breaker. Relevant data were sourced from NCC, Osogbo and a digital computer fault analysis program was applied. The circuit breakers considered are $S F_{6}$, Air, Oil and Vacuum and the designed criteria employed in the use of multi-criteria analysis are Cost, reliability, Flexibility and Environmental Impact. The Multi-Criteria Analysis (MCA) approach is an improvement over the traditional approach for calculating the symmetrical fault current at a system location and then selects a circuit breaker with a symmetrical interrupting capability equal to or above the calculated current. In the MCA approach, user preferences which take into account the design criteria were not ignored, as a result, a logical and rational approach has been developed for the Nigerian $330 \mathrm{kV}$ power system network which meets the input specifications and responds to user preference and concerns of power system operators.
\end{abstract}

Keywords: Power System, Circuit Breakers, Multi-criteria Analysis, Short-Circuit MVA, Three-phase Fault, Weighted Sum Average

\section{Introduction}

The Nigerian power system started experiencing a huge expansion since the deregulation regime started in the sector. The probability of faults on the expanded power system requires new device settings, coordinations, calculations and selections in order to withstand a fault. A fault is defined as any failure which interferes with the normal current flow in a power system [1]. A fault causes currents of high value (short-circuit current) to flow through the network to the faulted point. Short circuit currents generate heat proportional to the square of their magnitudes which damages the insulation of power system devices such as bus bars, cables, circuit breakers and switches [2].

Short circuit and protection studies are essential tools for the electric energy system engineer. The task is to calculate fault conditions and provide protective equipments designed to isolate the faulted zone from the remainder of the system in the appropriate time [3]. Even the most carefully designed power system may be subjected to damaging high magnitude current during a fault condition; to ensure that circuit protective equipments can isolate faults quickly and minimize system components damage, personnel hazard and outage severity, it is essential that a fault analysis be carried out in the electrical design [4].

The purpose of an electrical power system is to generate and supply electrical energy to customers with reliability and economy. The greatest threat to this purpose of a power system is the short circuit. When the system is so large like the Nigerian system considered in this paper, the chance of a fault occurring and the disturbance it will cause are both so enormous that without equipments to remove faults, the system will collapse [5]. The evaluation of fault currents and determination of circuit breaker ratings on a power system is therefore significant because the reliable and secure operations of the power systems depend on these.

Fault analysis can be broadly grouped into symmetrical and unsymmetrical faults. A fault involving all the three phases on the power system is known as symmetrical fault or three-phase fault while the one involving one or two phases is known as unsymmetrical fault. Single Line-to-ground, Line-to-line and Double line-toground faults are unsymmetrical faults [6][7]. The causes of faults are numerous and they include lightning, insulation aging, heavy winds, trees falling across lines, vehicles colliding with poles, birds, kites, etc. The effects of faults on power system are:

(i) Due to overheating and mechanical forces developed by faults, electrical equipments such as bus-bars, generators and transformers may be damaged.

(ii) The voltage profile of the system may be reduced to unacceptable limits as a result of fault. A frequency drop may lead to instability [8]. 
Majority of faults occurring on power systems are unsymmetrical faults, however, the circuit breaker rated megavolts ampere (MVA) breaking capacity is based on three-phase symmetrical faults. The reason is that a three-phase fault produces the greatest fault current and causes the greatest damage to a power system.

Traditionally, it is usually necessary to only calculate the symmetrical fault current at a system location, and then select a breaker with a symmetrical interrupting capability equal to or above the calculated current [9]. This approach has the shortcomings that it does not take into account aspects such as cost, reliability, flexibility and environmental impact. Thus there is a need for a broader based approach than the traditional one usually used in industry. Multi-criteria analysis (MCA) is a decision making process where several distinct criteria are usually involved when performing a selection or evaluation of a design. Criteria are distinct in the sense that they cannot be modelled through an explicit objective function [4].

MCA describes any structured approach used to determine overall preferences among alternative options, where the options accomplished several objectives. In MCA, desirable objectives are specified and corresponding attributes or indicators are identified. The actual measurement of indicators need not be in monetary terms, but are often based on the quantitative analysis (through scoring, ranking and weighting) of a wide range of qualitative impact categories and criteria [10].

When fault analysis is completed on the power system, the duty of the design engineer is to use the results to determine the ratings of the protective devices (Circuit Breakers) to interrupt the fault currents. The engineer will be left to choose between many alternatives (types of circuit breaker, costs, reliability, environmental impacts, and e.t.c.) and therefore would be left to result to the MCA Approaches. MCA methods have been applied to the analysis of power systems in various ways. Analytical Hierarchy Process (AHP) methodology was used to perform a comparison between different electricity power productions [11]. The Weighted Sum Model approach considered in this paper has also been employed as MCA methodology in the sizing and selection of circuit breakers [4]

The single line diagram of the Nigerian National Grid is shown in Figure 1 below.

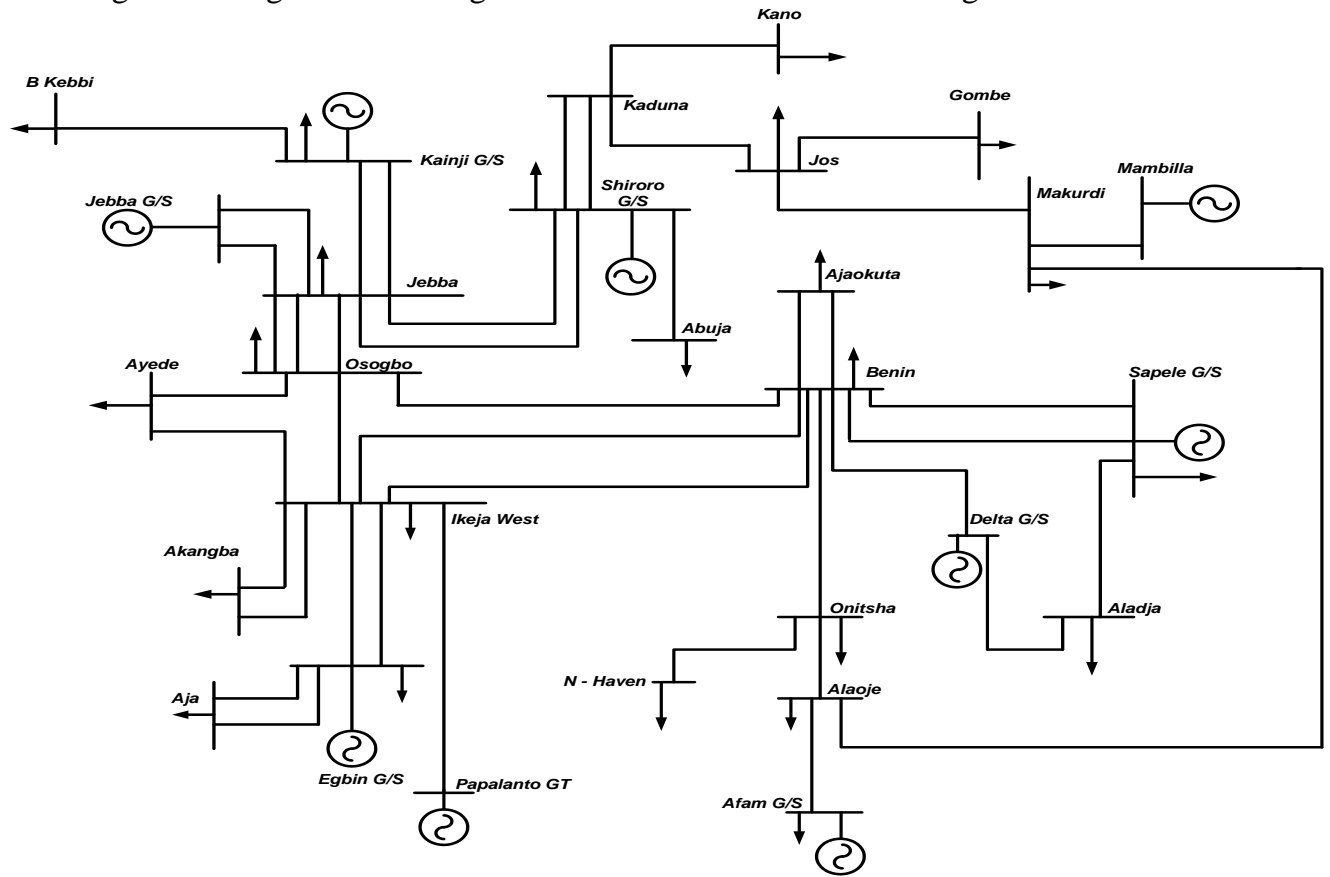

Figure 1: Nigerian 28 Bus 330kV National Grid

\section{Materials And Methods}

Determination of appropriate circuit breakers ratings for power system involves two power system analyses: Power Flow Analysis and Fault Analysis. Power Flow Analysis determines the initial conditions for Fault and Fault Analysis calculates fault currents magnitudes that are used to determine Short-Circuit Megavolt Ampere (SCMVA) ratings of appropriate circuit breakers.

The results of faults analysis are used in the determination of circuit breaker ratings selected on the power system. The circuit breaker rated MVA breaking capacity is based on three-phase symmetrical faults. For a symmetrical fault, the negative and zero sequences are absent. The positive sequence network present and modified for fault analysis is shown in Figure 2. 


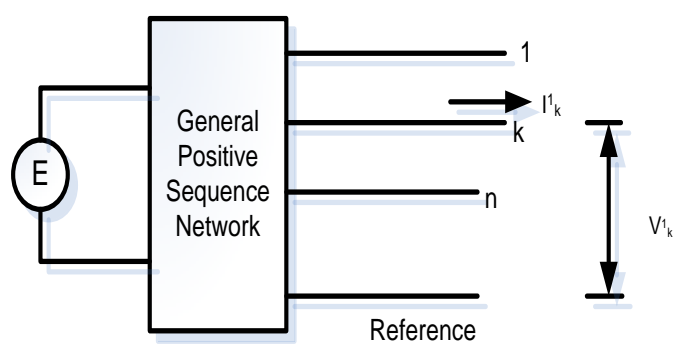

Figure 2: Positive Sequence Network Modified for Fault Analysis (Gupta, 2006)

The voltage at a bus is given as follows:

$\mathrm{V}^{1}{ }_{\mathrm{k}}=\mathrm{E}-\left(\mathrm{Z}_{\mathrm{k} 1}^{1} \mathrm{I}^{1}{ }_{1}+\mathrm{Z}_{\mathrm{k} 2}^{1} \mathrm{I}^{1}{ }_{2}+\ldots+\mathrm{Z}_{\mathrm{kk}}^{1} \mathrm{I}_{\mathrm{k}}{ }+\ldots+\mathrm{Z}_{\mathrm{kn}}^{1} \mathrm{I}_{\mathrm{n}}{ }^{1}\right)$

But all currents except at the faulted bus, i.e., $\mathrm{I}_{\mathrm{k}}^{1}$ are zero. Therefore,

$\mathrm{V}^{1}{ }_{\mathrm{k}}=\mathrm{E}-\mathrm{Z}_{\mathrm{kk}}^{1} \mathrm{I}_{\mathrm{k}}^{1}$

If $Z_{\mathrm{f}}$ is the fault impedance

$\mathrm{V}_{\mathrm{k}}^{1}=\mathrm{I}_{\mathrm{k}}^{1} \mathrm{Z}_{\mathrm{f}}$

From equations (2) and (3),

$\mathrm{I}_{\mathrm{k}}^{1}=\mathrm{E} / \mathrm{Z}_{\mathrm{kk}+}^{1} \mathrm{Z}_{\mathrm{f}}$

The voltage at $i^{\text {th }}$ bus is

$\mathrm{V}^{1}{ }_{\mathrm{k}}=\mathrm{E}-\mathrm{Z}_{\mathrm{kk}}^{1} \mathrm{I}_{\mathrm{k}}^{1}$

$$
=\mathrm{E}\left(1-\mathrm{Z}_{\mathrm{ik}}^{1} / \mathrm{Z}_{\mathrm{kk}+}^{1} \mathrm{Z}_{\mathrm{f}}\right)
$$

Where

$\mathrm{V}^{1}{ }_{\mathrm{k}}=$ Positive sequence bus voltage for bus $\mathrm{k}$.

$\mathrm{I}_{\mathrm{k}}^{1}=$ Positive sequence bus current for bus $\mathrm{k}$.

$\mathrm{Z}_{\mathrm{kk}}^{1}=$ Positive sequence bus impedance for bus $\mathrm{k}$.

$\mathrm{E}=$ Induced e.m.f. under load condition.

The short-circuit fault currents $\mathrm{I}_{\mathrm{k}}^{1}$ determined from equation (5) were converted to per unit values and the kA (Kilo-Amps) values were calculated from the following relations:

Base Current $=$ base MVA $/ \sqrt{ } 3$ X Base Voltage

Base MVA $=100 \mathrm{MVA}$

Base Voltage $=330 \mathrm{kV}$

Base Current $=100 \times 10^{6} / \sqrt{ } 3 \times 330 \times 10^{3}$

Base Current $=174.9546 \mathrm{~A}$

Actual Value of current $=$ Per Unit Value X Base Value.

Figure 3 shows the simplified computer flowcharts for calculating fault currents, voltages for the threephase fault considered and selecting appropriate circuit breakers.

Two of the circuit breaker ratings which require computations of short circuit currents are:

(i) Rated momentary current and

(ii) Rated symmetrical interrupting current.

Symmetrical short circuit current is obtained by using sub transient reactance for synchronous machines. Momentary current (rms) is then calculated by multiplying the symmetrical momentary current by a factor of 1.6 to account for the presence of dc offset current [13]. The current that a circuit breaker can interrupt is inversely proportional to the operating voltage over a certain range of time.

The voltage and current are in per unit values on a three-phase basis, then;

$\operatorname{SCMVA}(3-\Omega)=\mathrm{V}_{\text {prefault }} \times \mathrm{I}_{\mathrm{sc}} \mathrm{X}(\mathrm{MVA})_{\text {base }}$

Where

SCMVA = Short-Circuit Megavolts Ampere for three-phase,

$\mathrm{I}_{\mathrm{SC}}=$ Short-Circuit Current,

$(\mathrm{MVA})_{\text {base }}=$ Base MVA $=100 \mathrm{MVA}$.

Obviously, rated MVA interrupting capacity of a circuit breaker is to be more than (or equal to) to the short circuit MVA required to be interrupted. For the selection of a circuit breaker for a particular location, the maximum possible short circuit MVA to be interrupted must be found with respect to the type and location of fault and generating capacity connected to the system. A three-phase fault though rare is generally the one which gives the highest short circuit MVA and a circuit breaker must be capable of interrupting it.

The American National Standards Institute (ANSI) defines a circuit breaker as: "A mechanical switching device, capable of making, carrying and breaking currents under normal circuit conditions. Also capable of making and carrying for a specified time and breaking currents under specified abnormal circuit 
conditions, such as those of a short circuit." The International Electro-technical Commission (IEC) defines a circuit breaker as "a device designed to open and close a circuit by non-automatic means, and to open the circuit automatically on a predetermined over-current without damage to itself when properly applied within its rating." The types of circuit breakers available are Gas (SF6), Oil, Vacuum and Air circuit breakers and these were considered in this paper.

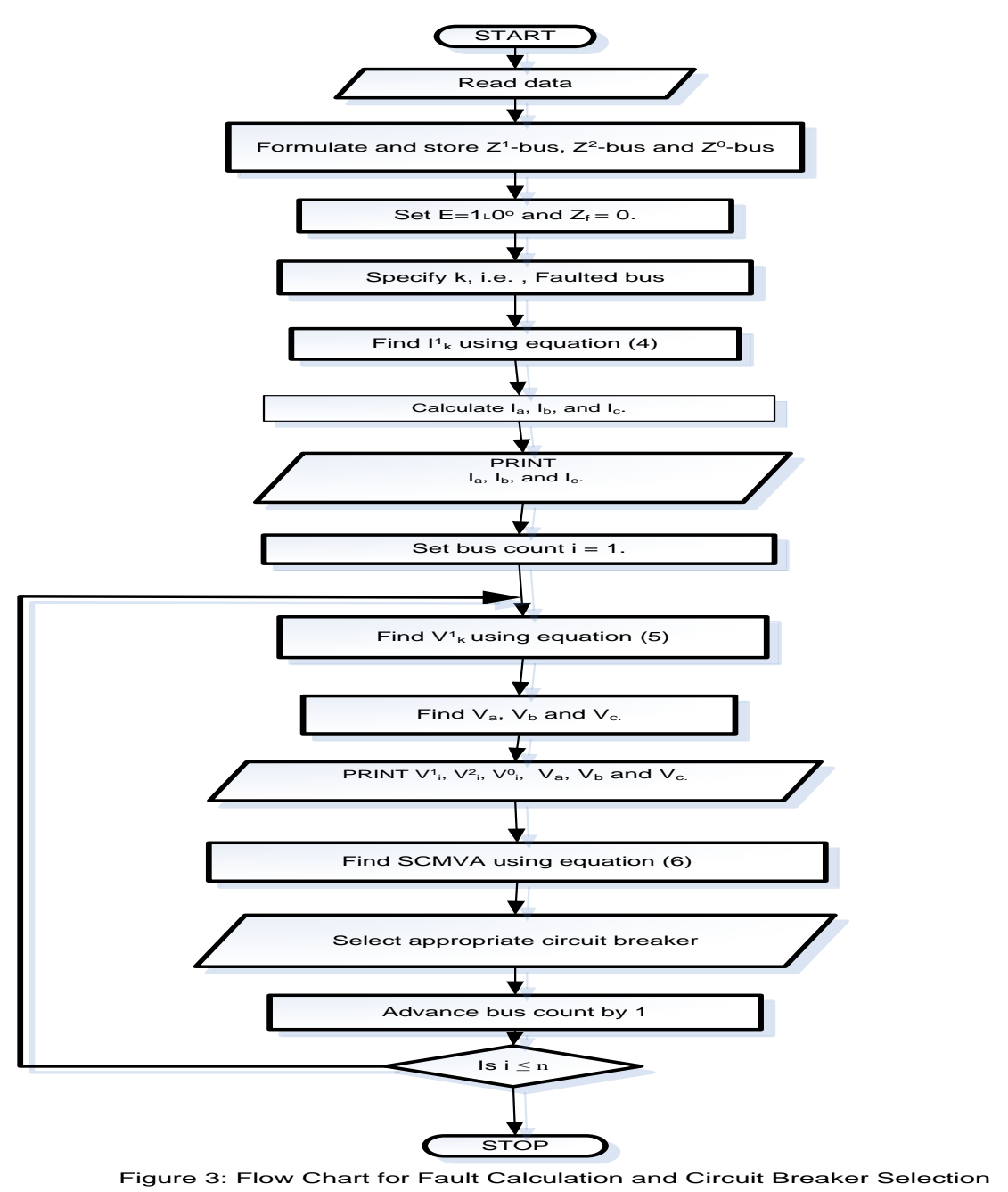

There exists various approaches to multi-criteria analysis but in this research work a weighted sum approach which is based on heuristic notions of relative scores and user preference weights will be used. This approach was found to be very suitable for implementation in power system planning and design and it is based on the formula below, (Jona and Atkinson-Hope, 2009).

Where;

$$
T_{s i}=\frac{1}{100} \sum_{k=1}^{4} R S_{i k} U P W_{k}
$$

$\mathrm{T}_{\mathrm{si}}=$ Total evaluation score of design $\mathrm{i}$ (normalized from 1 to 10 )

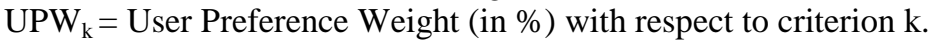

$\mathrm{RS}_{\mathrm{ik}}=$ Rated Score of the design $\mathrm{i}$ with respect to criterion $\mathrm{k}$.

In this research work, four criteria $(\mathrm{k})$ considered are Cost, Reliability, Operational Flexibility and Environmental Impact.

\section{Results And Discussion}

The three-phase Short Circuit MVA which determines the ratings of the Circuit Breaker to be installed were calculated using equation (6). Table 1 shows the Short Circuit MVA ratings for the fault currents on each bus and the corresponding ratings of the Circuit Breaker to be installed. 


\begin{tabular}{|c|c|c|c|}
\hline Bus No. & $\begin{array}{c}\text { Current } \\
\text { Magnitudes (kA) }\end{array}$ & $\begin{array}{l}\text { SCMVA } \\
\text { (MVA) }\end{array}$ & $\begin{array}{c}\text { Circuit Breaker Ratings } \\
\text { (MVA) }\end{array}$ \\
\hline 1 & 6.3 & 3800 & 4000 \\
\hline 2 & 4.6 & 2770 & 3000 \\
\hline 3 & 5.9 & 3541 & 3750 \\
\hline 4 & 6.9 & 3973 & 4000 \\
\hline 5 & 7.5 & 4372 & 4500 \\
\hline 6 & 3.2 & 1909 & 2000 \\
\hline 7 & 4.6 & 2745 & 2750 \\
\hline 8 & 6.3 & 3746 & 3750 \\
\hline 9 & 4.7 & 2614 & 2750 \\
\hline 10 & 5.9 & 3481 & 3500 \\
\hline 11 & 4.2 & 2537 & 2750 \\
\hline 12 & 4.4 & 2575 & 2750 \\
\hline 13 & 2.6 & 1440 & 1500 \\
\hline 14 & 4.3 & 2385 & 2500 \\
\hline 15 & 1.4 & 806 & 1000 \\
\hline 16 & 1.2 & 638 & 750 \\
\hline 17 & 5.5 & 3304 & 3500 \\
\hline 18 & 5.4 & 3236 & 3500 \\
\hline 19 & 3.1 & 1707 & 1750 \\
\hline 20 & 4.0 & 2291 & 2500 \\
\hline 21 & 4.3 & 2600 & 2750 \\
\hline 22 & 1.7 & 863 & 1000 \\
\hline 23 & 4.4 & 2719 & 2750 \\
\hline 24 & 5.6 & 3360 & 3500 \\
\hline 25 & 3.7 & 2046 & 2500 \\
\hline 26 & 2.8 & 1599 & 1750 \\
\hline 27 & 3.1 & 1876 & 2000 \\
\hline 28 & 6.3 & 3749 & 4000 \\
\hline
\end{tabular}

Each circuit breaker (design $i$ ) is assigned a relative score $\left(\mathrm{RS}_{i k}\right)$ as shown in Table 2, according to the four design criteria $(k)$. The scores are then weighted according to the user preference weights $\left(\mathrm{UPW}_{k}\right)$ as shown in Table 3, then total scores $\mathrm{TS}_{i}$ are obtained for the design, and then ranked according to these scores.

The relative scores were assigned to have 10 as the highest score and zero as the lowest. From Table 2, Vacuum circuit breaker is the cheapest in terms of cost with a value of 10 while $\mathrm{SF}_{6}$ is the costliest with a value of $5 . \mathrm{SF}_{6}$ is the most reliable with a score of 10 and Oil circuit breaker is the least reliable with a score of $3 . \mathrm{SF}_{6}$ is also the most flexible of the circuit breakers with a value of 8 while Air circuit breaker has the least flexibility with a value of 2 . Oil circuit breaker has the greatest impact on the environment with a value of 2 , it is inflammable and there is risk of fire, it may also form an explosive mixture with air, Vacuum circuit breaker is the safest in the environment with a value of 9.

Table 3 shows the user preferences given to each criterion by different users, Users A1 to A9. User A1 gave priority only to reliability, the user was only concerned with a reliably secured power system, cost and other criteria were not important. User A2 preferred the cheapest system at the expense of all other criteria. Users A3 and A4 gave preference only to flexibility and environmental impacts respectively. Users A5 - A9 gave preference to all the four criteria but stressing one over the others according to their experiences. User A9 was used in this research work because it represents what is mostly obtainable in industries; a reliable system that is not costly. It also considers the flexibility and the impact of the circuit breakers on the environment.

The practical application of MCA to select a Circuit Breaker is done by applying equation (7), on the relative scores and the user preference weights are shown in Tables 2 and 3, respectively. These scores are defined through an extensive consultation process where several experts in the field gave their judgement [14].

Table 2: Circuit Breaker Relative Scores

\begin{tabular}{|c|c|c|c|c|}
\hline \multirow{3}{*}{$\begin{array}{l}\text { Design i } \\
\text { Circuit Breaker } \\
\text { Insulating Medium }\end{array}$} & \multicolumn{3}{|c|}{ Criteria (k) (1 to 4$)$} & \multirow[b]{2}{*}{$\begin{array}{l}\text { Environmenta } \\
\text { Impact }\end{array}$} \\
\hline & Cost & Reliability & Flexibility & \\
\hline & \multicolumn{3}{|c|}{ Relative Score $\left(\mathrm{RS}_{\mathrm{ik}}\right)$} & \\
\hline $\mathrm{SF}_{6}$ & 5 & 10 & 8 & 8 \\
\hline Oil & 9 & 3 & 5 & 2 \\
\hline Vacuum & 10 & 8 & 6 & 9 \\
\hline Air & 6 & 4 & 2 & 4 \\
\hline
\end{tabular}


Aplication Of Multi-Criteriaanalysis For Circuit Breaker Selection On Nigerian National Grid

\begin{tabular}{lllll}
\multicolumn{5}{c}{ Table 3: User Preference Weights (\%) } \\
\hline User Preference & Cost & Reliability & Flexibility & $\begin{array}{l}\text { Environmental } \\
\text { Impact }\end{array}$ \\
\hline A1 & 0 & & & 0 \\
A2 & 100 & 100 & 0 & 0 \\
A3 & 0 & 0 & 0 & 0 \\
A4 & 0 & 0 & 100 & 100 \\
A5 & 40 & 30 & 0 & 10 \\
A6 & 30 & 20 & 20 & 10 \\
A7 & 10 & 50 & 40 & 10 \\
A8 & 10 & 10 & 30 & 50 \\
A9 & 30 & 45 & 30 & 10 \\
\hline
\end{tabular}

In industry, cost and reliability criteria are the main stressed preferences besides flexibility and environmental impacts, thus the four criteria of A9 preference will be used to choose a Circuit Breaker. Using the $\mathrm{SF}_{6}$ circuit breaker as an example, the result is obtained by multiplying the corresponding factors which are then summed together to get the total score. The cost relative score of breaker is multiplied by the percentage of user preference weight, and the same applies to the other three aspects. The individual totals are then added together to get a total score TS for the breaker, namely:

$$
T S_{S F_{6}}=\frac{(30 X 5+45 X 10+15 X 8+10 X 8)}{100}=8.00
$$

It can be seen that the terms one to four in the equation represent the products of cost, reliability, flexibility and environment from Tables 2 and 3, respectively. The equation is then applied to the other breakers. The circuit breaker with highest TS is then selected. Table 4 shows the results of the whole insulation medium total scores for the A9 preferences.

Table 4: Result Evaluation of different Breakers For User A9

\begin{tabular}{llllll}
\hline \multicolumn{5}{c}{ Multi-Criteria Evaluation } \\
\hline Type & Cost & Reliability & Flexibility & $\begin{array}{l}\text { Environmental } \\
\text { Impact }\end{array}$ & $\begin{array}{l}\text { Total Score } \\
\text { (TS) }\end{array}$ \\
\hline SF $_{6}$ & $0.30 * 5$ & $0.45 * 10$ & $0.15 * 8$ & $0.10 * 8$ & 8.00 \\
Oil & $0.30 * 9$ & $0.45 * 3$ & $0.15 * 5$ & $0.10 * 2$ & 5.00 \\
Vacuum & $0.30 * 8$ & $0.45 * 8$ & $0.15 * 6$ & $0.10 * 9$ & 7.30 \\
Air & $0.30 * 6$ & $0.45 * 4$ & $0.15 * 2$ & $0.10 * 4$ & 4.30 \\
\hline Total & 8.40 & 11.25 & 3.15 & 2.30 & \\
\hline
\end{tabular}

The results from Table 4 are in conformity with the modern trend in power systems. SF6 circuit breaker is more favoured than other types because there is no risk of explosion/fire, it is smaller in size, requires minimum lubrications for control devices, excellent reliability and less impact on the environment since they are sealed in an enclosure (Hewitson, et al, 2004). It can be seen from the evaluation in Table 4 that the " $\mathrm{SF}_{6}$ " circuit breaker exhibits a slight advantage over the others. It can be seen from the totals that the cost (8.40) and reliability (11.25) criteria have a greater impact on the selection of CB. However the flexibility (3.15) and environmental Impact (2.30) cannot be ignored. From the fault analysis results, circuit breakers can now be selected based on their electrical specification. This is done after the suitable Circuit Breaker type has been identified using the MCA approach based on the preferred criteria [4].

\section{Conclusion}

In this study, fault analysis on the Nigerian $330 \mathrm{kV}$ power system network was carried out; the results of the analysis were used to determine the ratings of the circuit breakers needed to be installed on the system. The Multi-Criteria Analysis method using the Weighted Sum approach was used to support the decision making process of sizing and selecting a circuit breaker. This method proved to be useful and effective.

The Multi-Criteria Analysis approaches is an improvement over the traditional approach of calculating the symmetrical fault current at a system location and then select a circuit breaker with a symmetrical interrupting capability equal to or above the calculated current (Glover and Sarma, 1989). In the MCA approach, user preferences which take into account the design criteria were not ignored. As a result, a logical and rational approach has been developed for the Nigerian $330 \mathrm{kV}$ power system network which meets the input specifications and responds to user preference and concerns of the user. 


\section{References}

[1] Muhammad, Aree A. (2011), "Simulation of Different Types of Faults on Northern Iraq Power System', IGEC VI - 2011 - 028

[2] Ibe, A.O. and Uzonwa, N.K. (2005), "Power System Simulation for Short Circuit Current in the Selection of Switchgears", Nigerian Journal of Industrial and Systems Studies, Vol. 4, No. 3, pp $9-15$.

[3] El-Hawary, M.E. (2008), "Introduction to Electrical Power System', Wiley, IEEE Press.

[4] Jona, J. and Atkinson-Hope, G. (2009), "Multi-Criteria Analysis for the Sizing and Selection of Circuit Breakers in Power Systems", International Journal of Innovation in Energy Systems and Power. Vol. 4, No. 1, pp $9-13$.

[5] Hewitson Les, Brown Mark and Ramesh Ben, (2004), "Practical Power System Protection", IDC Technologies.

[6] Okelola, M.O., Yussuf, A.A., and Awosope, C.O.A. (2005), “Fault Analysis: An Application of Venin's Method to 330kV Transmission Grid System in Nigeria', LAUTECH Journal of Engineering and Technology, Vol. 3, No. 1, pp 30 - 43.

[7] Tijani M.A. and Olatunji D.O. (2011), "An Evaluation of Three-Phase Fault Currents on the Nigerian 330kV Transmission Grid". Journal of Research in Technology and Engineering Management, Vol. 4, No. 2, pp. 37 - 45.

[8] Okemiri, O.N., (2008), "Basic Protection Scheme on Power System', The Nigerian Tribune, Tuesday $12^{\text {th }}$ February 2008 , pp 24.

[9] Glover J.D., and Sarma M., (1989), "Power System Analysis and Design”, PWS-KENT, Wadworth, Inc.

[10] http/www.dtlr.gov.uk/multicriteria/index.htm

[11] Bilal, A.A., Rustom, M. and Mousa, S.M. (1998), "Multi-criteria Selection of Electric Power Plants Using Analytical Hierachy Process", Electric Power System Research 52, pp 29 - 35.

[12] Gupta, B.R. (2006), "Power System Analysis and Design”, S. Chand and Company Ltd. India.

[13] Nagrath, I.J. and Kothari, D.P. (1994), “Power System Engineering”, Tata McGraw-Hill Publishing Company Limited, New Delhi.

[14] Atanakovic, D., McGillis D.T., and Galiana F.D., (1998), "The Application of Multi-Criteria Analysis to Substation Design", IEEE Transaction on Power System, Vol. 13, No. 3. 